\title{
Releyendo la turbodolarización: una concertación mutilada
}

Cristina Rivera

Departamento de Economía UCA, San Salvador

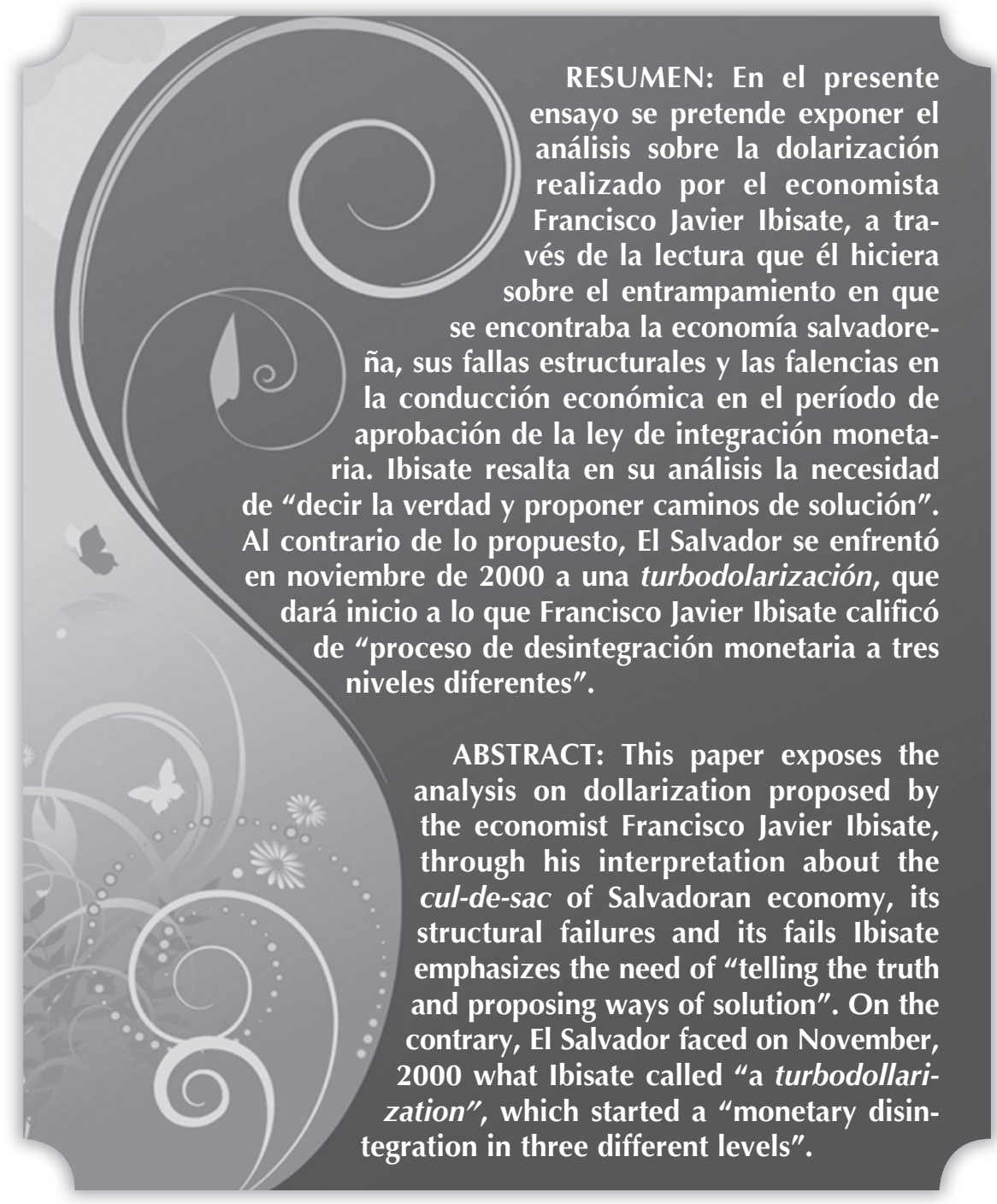


isionario como lo fue, Ibisate se adelantó a la historia actual. Afirmó que diez años después de aprobarse la ley de integración monetaria (LIM), "cuando [...] un ecuánime analista recoja los hechos principales de la presente y pasada década, podría titular así el capítulo tercero de su obra: 'Y después vino la dolarización'. Sin duda, este historiador nos va a decir cosas que ahora ignoramos, porque estamos en la era de las promesas, de las dudas y de las posibles expectativas. Todo esto ha sido tan rápido, tan brusco, tan inconsulto, que nuestro historiador va a saber mucho más que nosotros" (Ibisate, 2000: 1999).

De ese modo, él dejó claves fundamentales para el análisis, al señalar pistas para "ayudarle ly en este caso ayudarnos] a hacer arqueología histórica de los capítulos primero y segundo de la misma historia [...] el capítulo tercero será una 'coyuntura', [el momento presente: 2011] un resultado futuro o conjunción de los hechos, políticas y medidas adoptadas por los gestores de los dos primeros capítulos, en este caso escritos por el mismo partido y los mismos gobiernos" (Ídem).

Para comprender el proceso de dolarización en El Salvador, nuestro economista nos habría recordado el discurso pronunciado por el entonces mandatario Francisco Flores en el año 2000, cuando afirmó: "todos en el país sabemos que nuestra economía, después de lograr éxitos muy marcados, está experimentando un entrampamiento que ha generado un negativismo muy nocivo para el desarrollo del país. No puede culparse a nuestros sectores productivos de este entrampamiento, ya que todas nuestras fuerzas económicas - los obreros, los empresarios, los agricultoreshan dejado muy clara su dedicación al trabajo y al desarrollo del país" (Ídem). De este modo, en su análisis, Ibisate reconocía la situación de entrampamiento de nuestra economía, enfatizando las implicaciones de esta palabra, pues significa que la economía "cayó en una trampa y no logra escapar de" ella. De ahí que la pregunta indispensable que él se plantea es "¿quién inventó y quién puso la trampa?". En vista de que el discurso del entonces presidente Flores deslinda de responsabilidades a todas nuestras fuerzas económicas, el padre Ibisate concluye acertadamente que "sólo queda un gran culpable: el modelo económico y la conducción del modelo, timoneado por los tres últimos gobiernos. Ésta es la conclusión lógica que se deriva del discurso presidencial, que deja un espacio de culpabilidad al sistema bancario, no citado entre las fuerzas económicas productivas" (Ídem). Ha sido "la profecía del modelo de propiedad privada: 'más mercado libre, más libre competencia, más Estado subsidiario del mercado', [la que] nos ha llevado a una economía entrampada": ha sido el modelo 
económico y su conducción el que inventó y puso la trampa.

Es preciso recordar que con anterioridad a la aprobación de la LIM, el padre Ibisate venía señalando una serie de límites internos del crecimiento económico nacional; por ejemplo "la terciarización de la economía salvadoreña, la desolación agraria y la despreocupación que el sector bancario mantiene en la canalización del crédito a los sectores más tradicionales" (Ibisate, 1998). Al respecto, destacaba la función pública del sector bancario privado, en tanto emplea y se beneficia de un ahorro público o nacional, que, por tanto, debería canalizar - a través del crédito- hacia la dinamización de las actividades productivas con mayor generación de valor agregado, empleo e ingresos nacionales. Sin embargo, señala: "ésta no ha sido la conducta de la banca privada", de ahí que identificara en el crédito bancario otro límite al crecimiento, puesto que "ha tenido un destino preferencial hacia las actividades de servicio" y no se ha empleado en actividades relacionadas con la producción material. Esto ha evidenciado que en la década de los noventa se profundizó "la búsqueda de la rentabilidad a corto plazo". A la luz de estas reflexiones indicaba que "el problema mayor está en el comportamiento oligopólico de la banca privada" y concluía que "tampoco es cierto que nuestro sistema bancario sea sólido, cuando más bien ha con- tribuido a un mayor debilitamiento de la estructura productiva". Ante esta situación, trasladamos en este comentario su recomendación aún vigente: la política estatal en el ámbito financiero debe tener como fin último "apoyar el mejoramiento de las condiciones de la vida de la población".

Asimismo, el economista señaló una serie de fallas estructurales de la economía salvadoreña. Entre ellas, situaba la insatisfacción de las necesidades básicas familiares, la desintegración sectorial, y la desatención a la demanda popular. De ahí que en 1998 destacara la necesidad de que las propuestas económicas "vuelvan a enfatizar medidas concretas hacia la integración sectorial, so pena de derivar en una economía imposible", puesto que la economía nacional estaba Ilegando a un "entrecruce de callejones sin salida: la terciarización económica, que a la vez fomenta y precede del rezago tecnológico, afectados ambos limitantes por la depredación del medio ambiente y el contrasentido del crédito bancario, [que] nos ha llevado a la reducción de nichos productivos para la inversión productiva" y estaba orientándose a la inversión financiera de carácter especulativo.

Además, Ibisate logró identificar en 1998 serios fallos en la conducción económica: no hay un plan nacional de desarrollo, no hay una visión de mediano y largo pla- 
zo, estabilidad y confianza, existe un enorme desafío en materia de empleo y bienestar social y de mejora en las condiciones de vida de la población.

Un año antes de la presentación de la LIM, el padre Ibisate presentó unas reflexiones sobre la coyuntura económica de 1999, en las cuales indicaba los frutos que recogía la economía salvadoreña de todas las acciones emprendidas durante la década de los noventa. Expresamente partía del reconocimiento de una serie de rasgos que evidenciaban la debilidad económica. De acuerdo a su análisis "harían falta aproximadamente siete siglos para que se duplicara el consumo por habitante", señalando que "nuestro crecimiento económico es muy débil y por lo tanto difícilmente podrá superar los problemas de desempleo y de pobreza de la mayor parte de la población".

A lo anterior debe agregarse la necesidad imperativa para la población de "ejercer el derecho a trabajar". De ahí que en su artículo "Teoría general del subempleo, el desinterés y la moneda" señalara que el modelo aplicado en el tercer mundo sea el de "pleno subempleo [que] tiene por nombre sector informal". Esta problemática continúa agravándose: según los resultados de la encuesta de hogares de propósitos múltiples, para 2009, el 34\% de la población económicamente activa (PEA) en el área urbana se encontraba en una situación de subempleo; es decir, que de cada cien personas de la PEA, 34 personas obtienen un ingreso inferior al salario mínimo vigente a pesar de trabajar 40 horas semanales, o más (situación de subempleo invisible que afecta al $26.9 \%$ de la PEA), o -en el caso de subempleo visible, que afecta al $7.1 \%$ de la PEA- por laborar menos de cuarenta horas a la semana de forma involuntaria.

Por su parte, el desempleo a nivel nacional afectaba en 2009 al $7.3 \%$ de la PEA, es decir, a 187,088 personas.

Desde 1999, esta situación se veía afectada por el hecho de que "los salarios reales mínimo y promedio [habían] permanecido estancados en su poder de compra por una década entera", evidenciando que "el modelo económico de los noventas ha sido un modelo de crecimiento marginador y excluyente". Desde 1999, el cambio en los salarios promedio mensuales, ha presentado una modesta variación, elevándose de \$225.07 a $\$ 277.63$ en 2009; sin embargo, el poder adquisitivo de estos salarios se ha deteriorado de $\$ 146.67$ a $\$ 127.61$. Por su parte, en el mismo período, los salarios modales — de especial representatividad, pues indican los salarios que el grueso de la población salvadoreña percibe- han mostrado un precario 
aumento en su poder de compra, al subir de $\$ 64.87$ a $\$ 85.03$ en términos reales.

Si a esto añadimos el peso del crecimiento en el costo de adquisición de los bienes y servicios necesarios para permitir que los trabajadores repongan el gasto físico y mental que realizan durante el proceso de trabajo $-y$ con ello, garantizar el sustento y la reproducción adecuada de la fuerza de trabajo personal y familiar- identificamos una presión sustantiva, ya que — de acuerdo a las últimas cifras disponibles presentadas por la DIGESTYC al mes de diciembre de 2009- adquirir la canasta de mercado implicaba un desembolso de $\$ 759.5$, mientras que en el mismo mes del año 1999 se sufragaba con $\$ 535.67$. Cifras presentadas por la Dirección General de Estadísticas y Censos, DIGESTYC, para el mes de marzo de 2011, indican que la inflación punto a punto - medida por la variación porcentual del índice de precios al consumidor (IPC) — ha sido 2.72\%; sin embargo, debe prestarse particular atención a las divisiones más afectadas por el alza de precios: en primer lugar, el rubro de transporte - con un $6.24 \%$ - , seguido por el de alimentos y bebidas no alcohólicas - con un $5.85 \%$. Esto denota la gravedad de la situación, por tratarse de rubros que tienen un mayor peso en la distribución del consumo familiar. Si integramos la información anterior, se deduce que la reflexión que hiciera Ibisate en 1979 continúa vigente: los precios suben por el ascensor, mientras los salarios lo hacen por la escalera.

A estas problemáticas, el padre Ibisate sumaba la mora bancaria, que había alcanzado en 1999 un "promedio de $6.37 \%$ cuando la norma es no sobrepasar un $3 \% "$; asimismo, se añaden los problemas de déficit fiscal -o "situación de pobreza" del erario público- y déficit comercial. Así, concluía su análisis con la convicción de que "para sanear nuestra economía es preciso comenzar a decir la verdad y proponer caminos de solución".

Sin embargo, haciendo oídos sordos a este llamado, en noviembre de 2000 el Órgano Ejecutivo optó por un "golpe de timón", mediante la apresurada aprobación con mayoría simple en la Asamblea Legislativa de la Ley de Integración Monetaria (por medio del Decreto $N^{\circ} 201$ fechado el 30 de noviembre de 2000), a tan sólo ocho días de haber sido presentada públicamente -el 22 de noviembre del año 2000. De este modo, la economía salvadoreña cedió su soberanía monetaria y se vio atravesada por un proceso de "dolarización disfrazada y contra el reloj", de ahí que el Padre Ibisate acuñara el término "turbodolarización" (Ibisate, 2001a).

Según la tesis propuesta por el economista (2001a: 12), "la turbo- 
dolarización se explica porque el presente Gobierno tiene miedo de sí mismo", es así como, citando al periodista Laffite Fernández, enfatizaba: "no hay duda que, ante el negativismo, la frustración y la caída libre por la que parecía transitar la economía, el Gobierno apostó a un proyecto que manejó durante los últimos ocho meses, en silencio". En vista de lo anterior, Padre Ibisate previó que la LIM podría "regresar a modo de bumerán, contra el gobierno que la editó y los partidos que la aprobaron" (2000: 2106); especialmente porque no es posible honrar "a un gobierno que utilizó la política monetaria restrictiva para elevar las tasas de interés, frenar la economía y después justificar su dolarización. Lo dictatorial de este comportamiento es que, al mismo tiempo que se rompe un proceso de concertación civil, se pacta un sucio convenio legislativo para la pronta aprobación de la ley" (Ibisate, 2001 a: 21).

Además, el gobierno había generado demasiadas expectativas, que chocan con las dificultades reales puesto que un decreto de integración monetaria resulta incapaz de resolver las problemáticas estructurales de la economía salvadoreña, especialmente porque, según explicaba el autor, el proyecto "se inicia con un proceso de desintegración monetaria a tres niveles diferentes" (2000: 1203):
Desintegración del colón, es decir, de la moneda nacional, condenada a una pronta eutanasia. En este punto conviene recordar que, según señaló Ibisate: "la moneda no es sólo una medida de valor, sino una medida de valores; no es sólo un instrumento de cambio de mercancías, sino un modo de relacionarse las personas; no es sólo un ahorro o patrón de pagos diferidos, sino una seguridad personal para el futuro. $Y$ con la pérdida de valor de la moneda [...] se debilitan los valores morales de las personas" (1979: 125). Aunque este análisis lo aplicó al caso de la inflación, también se evidenció en el proceso de transición bimonetarista a través del mecanismo de "redondeo de los precios con tendencia al alza", situación que no se hizo acompañar por redondeo hacia arriba de los salarios de la clase trabajadora, en vista de la característica demanda deprimida de la población. Como él mismo aclaró (2000: 1204), la existencia de esta baja demanda no hacía más acertada la afirmación de que "hasta hoy han existido dos monedas en el país: la moneda de los ricos (el dólar) y la moneda de los pobres (el colón)", puesto que para el año 2000, los " $\$ 1,500$ millones de las remesas anuales los crean los [salvadoreños y salvadoreñas] pobres de afuera". Al cerrar el año 2010, las remesas familiares totalizaron $\$ 3,430.9$ millones, y a marzo de 2011 ya alcanzaron los $\$ 865.8$ millones, hecho que como 
- como señalara el Padre Ibisate (2003) — "deja malparada a nuestra economía nacional". Ello es así pues la masiva emigración salvadoreña constituye una muestra de la falta de posibilidades nacionales que las personas encuentran para desarrollar su potencial productivo y satisfacer de manera adecuada sus necesidades personales y las de su grupo familiar, tanto en el plano de la subsistencia, como en el de la participación, la protección, etc.; y a la vez, son justamente las remesas familiares enviadas por nuestros compatriotas, las que mantienen a flote nuestra economía. De ahí que concluyera que "los pobres desempleados, que no encuentran pan ni trabajo en su patria, son los que sostienen una economía que no logra dar pan y trabajo a los 'hermanos cercanos'" (Ibisate, 2003).

Desintegración de la política monetaria, pues el Banco Central de Reserva deja de ser el "banco de la nación, banco de bancos y prestamista en última instancia. [De este modo] se pierden las principales medidas de política monetaria en un momento en que se venía hablando y pidiendo la autonomía y apoliticidad del BCR [...] cuando lo que necesitábamos era otro Banco Central, pero no un mini-banco central" (Ibisate, 2000: 1205). En este contexto, ante la interrogante: "¿qué ocurriría si hay una crisis económica en Estados Unidos?", Ibisate respondía: "aguantarla, [pues] el secretario del Tesoro de Estados
Unidos ya ha dicho que manejarán su política monetaria de acuerdo a sus necesidades" (Ibisate, 2001b).

Desintegración de la integración económica centroamericana, puesto que la medida se adoptaba de forma inconsulta (Ibisate, 2000: 1205). Además, "la moneda, siendo tan nacional como la bandera, era al mismo tiempo, portadora de relaciones internacionales" (Ibisate, 1979: 125), cuya definición queda ahora más supeditada al desenvolvimiento de la economía Estadounidense.

En el camino recorrido, no se ha logrado "la paz del trabajo y del pan compartido" (Ibisate, 2003). Por ello se impone la necesidad de "reorganizar una economía más equitativa", de tal modo que se generen las condiciones en las que "todos puedan tener acceso a los tres tiempos de comida y al trabajo de cada día", posibilitando la reproducción de su vida de manera digna, sin que la opción de emigrar se constituya en la única salida para miles de salvadoreños para quienes su país de origen no les ha permitido acceder a las condiciones mínimas de subsistencia.

Diez años después de la entrada en vigor de la LIM, sirvan estas referencias para iniciar la reflexión sobre los efectos que ha generado la dolarización en la economía salvadoreña, y de qué manera se ha manifestado sobre las posibilidades de reactivación económica, las tasas de 
interés, la producción e inversión y la competitividad nacional, y contribuirán a comprender por qué es necesario hablar del "malestar en la dolarización" (Ibisate, 2002-2003).

A expresa solicitud del padre Ibisate, finalizo mi intervención reafirmando sus palabras: "si la

\section{Referencias:}

Ibisate, Francisco Javier (1979); "Inflación monetaria y deflación cívica" en Boletín de Ciencias Económicas y Sociales". № 16, septiembre, pp. 125 y 130.

(1998); "El crédito bancario: otro límite al crecimiento" en Semanario Orientación. 13 y 20 de septiembre, pp. 5.

(1999); "La coyuntura económica 1999. ¿Vamos a mejor, o vamos Dios sabe a dónde?" en Semanario Orientación. Nos. 50975101, 17, 24, 31 de octubre; 7 y 14 de noviembre.

(2000); "Teoría general del subempleo, el desinterés y la moneda" en Realidad. № 75, Mayojunio, pp.243-276.

$$
\text { (2000); "Y después }
$$
vino 'la dolarización'" en ECA. $\mathrm{N}^{\circ}$ 625-626, noviembre-diciembre, pp. 1199-1206. economía está entrampada, ello es culpa de quienes han dirigido y han controlado la conducción del modelo para sus propios fines. Nuestro historiador nos contará cómo acabó todo en el año 2010. Ojalá diga que el proceso de dolarización comenzó como una 'concertación mutilada'” (Ibisate, 2000: 1206). dolarización'" en Realidad. № 79, enero-febrero, pp. 9-29.

. (2001 b); "La dolarización y sus consecuencias" en Carta a las Iglesias. $N^{\circ} 465,1^{\circ}-15$ de enero, p. 6.

fectos de la dolarización" "Los efectos de la dolarización" en Semanario Orientación. Nos. 52515255, ediciones de los días 1, 8, 15 y 22 de diciembre 2002 y 5 de enero 2003.

(2003); “La oración del salario mínimo: 'Danos hoy el pan nuestro de cada día"" en Carta a las Iglesias. No 518 , junio, p. 2.

Ley de Integración Monetaria, Decreto $N^{\circ} 201,30$ de noviembre del 2000; publicado en el Diario Oficial № 241, Tomo 349 del 22 de diciembre de 2000. 